\title{
Ustekinumab as an Alternative Treatment Option for Chronic Pityriasis Rubra Pilaris
}

\author{
Mudit Chowdhary Ulysses Davila David J. Cohen \\ Division of Dermatology, Department of Internal Medicine, Mercer University School of \\ Medicine, Macon, Ga., USA
}

\section{Key Words}

Pityriasis rubra pilaris · Ustekinumab · Alternative treatment

\begin{abstract}
Pityriasis rubra pilaris (PRP) is an exceptionally rare, chronic inflammatory dermatosis of unknown etiology. Patients classically present with small, follicular keratosis and salmoncolored plaques that begin at the head and neck and slowly progress to widespread erythroderma including the palms and soles. It is difficult to distinguish PRP from other inflammatory dermatoses; however, features that help aid in the diagnosis include 'islands' of spared skin, orangish hue and typical findings on biopsy. There are no specific guidelines on therapy and treatment options include corticosteroids, vitamin D analogs, retinoids, methotrexate, cyclosporine, azathioprine and tumor necrosis factor alpha antagonists. Unfortunately options are limited for patients when these drugs do not work. We report a case of chronic PRP, refractory to conventional treatment, successfully treated with ustekinumab monotherapy. The patient was treated with $90 \mathrm{mg}$ subcutaneous ustekinumab injections and began to show improvement within only 8 weeks. Long-term control of the disease has been attained without any significant side effects. We report this case to show that ustekinumab can be used as an alternative treatment method for patients with chronic, unremitting PRP. Treatment response is remarkably rapid and the infrequent dosing leads to patient compliance and a significantly improved quality of life.


Case Reports in
Dermatology

\begin{tabular}{l|l}
\hline \multicolumn{2}{l}{ Case Rep Dermatol 2015;7:46-50 } \\
\hline DOI: 10.1159/000381011 & $\begin{array}{l}\text { ○ 2015 S. Karger AG, Basel } \\
\text { www.karger.com/cde }\end{array}$ \\
\hline
\end{tabular}

Chowdhary et al.: Ustekinumab as an Alternative Treatment Option for Chronic Pityriasis Rubra Pilaris

\section{Introduction}

Pityriasis rubra pilaris (PRP) is a rare inflammatory dermatosis of unknown etiology and substantial heterogeneity. A definitive pathogenesis of PRP has yet to be found, but one suggested etiology thought to play a role in PRP is T-cell-mediated immunity [1]. PRP is divided into a spectrum of six subtypes that are defined by age of onset, lesion characteristics, disease course and association with HIV, type 1 being the most common and classic form in adults.

Typically, these patients present in adulthood with small, follicular keratosis, moderate to large erythroderma, salmon-colored plaques with or without scaling, and keratoderma of the palms and soles with an orange discoloration. Lesions are well circumscribed with areas of spared skin. Often these patches start at the head and neck and progress to include the trunk and extremities.

The management of PRP consists of combination topical and systemic therapies; however, there are no specific guidelines or controlled trials for treatment. Effective therapies include corticosteroids, vitamin D analogs, retinoids, pimecrolimus, methotrexate, cyclosporine and azathioprine [2]. Tumor necrosis factor antagonists (infliximab, etanercept and adalimumab) have also been proven to be successful in more severe cases [1,3].

For PRP that does not remit, treatment options are limited and are largely based on anecdotal reports. Ustekinumab is a monoclonal antibody that is approved for the treatment of psoriasis, but has been shown to be effective as an off-label treatment for PRP [4].

We report a case of type 1 PRP that was unresponsive to first- and second-line treatment, but demonstrated complete resolution with long-term use of ustekinumab, a treatment for this disorder underrepresented in the literature.

\section{Case Presentation}

A 52-year-old African-American female developed acute onset of diffuse, salmoncolored rash on her trunk. Within 12 weeks her rash progressed to involve her entire head and trunk, and after another 8 weeks involved both upper and lower extremities. Sparse 'islands' of spared skin were present within the erythematous areas. The palms and soles were noted to be hyperkeratotic with associated nail dystrophy. Additionally, her skin had become painful and scaly and she began to develop scattered alopecia areata. She did not have evidence of any active infectious event over this time, nor was there any other medical comorbidity.

Skin biopsy demonstrated hyperkeratosis alternating horizontally and vertically along with epidermal hyperplasia. Clinical and laboratory testing ruled out any underlying immunodeficiency or malignancy. The patient was subsequently diagnosed with PRP type 1 based on her presentation and histopathology ruling out more common etiologies, including psoriasis. She was started on acitretin (50 mg/day) and scheduled for follow-up.

Unfortunately the patient's erythroderma and follicular papules persisted over the following 8 years. During that time she also underwent trials with emollients, narrow-band UVB phototherapy, minocycline, prednisone, clobetasol propionate and methotrexate. Her condition severely limited her daily activities, including loss of employment, so another treatment option was considered.

After being explained the risks of treatment, the patient consented to a single ustekinumab $90 \mathrm{mg}$ injection subcutaneously, which was re-administered at 4 weeks and then 
Chowdhary et al.: Ustekinumab as an Alternative Treatment Option for Chronic Pityriasis Rubra Pilaris

quarterly. Her rash diminished significantly within 8 weeks (fig. 1) and she reported feeling much less pain. On examination, body erythema had decreased from $>95 \%$ to $15 \%$.

Our patient continues to receive a single $90 \mathrm{mg}$ intramuscular injection doses of ustekinumab in the office every 12 weeks and she is monitored for side effects throughout, including but not limited to nasopharyngitis, upper respiratory tract infection, headache, fatigue and nausea. To date she remains mildly symptomatic with coalescing orange-salmoncolored rashes with islands of sparing involving $<5 \%$ of the body. Overall, she has improved remarkably and has noted a significant increase in her quality of life, including regaining employment.

\section{Discussion}

The pathogenesis of PRP is unknown and the majority of information on this disorder's etiology is based on its clinical response to existing treatment modalities. PRP is best explained as an immunologic disorder; however, no definitive source has been identified, which explains the vast amount of treatment options. Conventional treatments for PRP include topical therapies, such as emollients, corticosteroids, vitamin D analogs (calcipotriene), retinoids and pimecrolimus, combined with systemic therapies such as methotrexate, cyclosporine and azathioprine. Up to $80 \%$ of type 1 PRP resolves without treatment within 3 years [3]. In some cases however, PRP does not remit and treatment options for these patients are limited. Recently, tumor necrosis factor alpha inhibitors have been used with some success, further supporting the immunologic hypothesis [3]. Regardless, all of these therapeutic options have showed varied levels of success [5] and long-term use of each can lead to significant side effects.

PRP shares many features with psoriasis, such as widespread, scaly plaques, and must be differentiated by a good clinical history and physical and skin biopsy. Histopathology is also helpful, with PRP showing characteristic 'checkerboard' areas of hyperparakeratosis. Nevertheless, many of the treatment options that have been employed are based on the many similarities, including presentation, that PRP shares with psoriasis.

Ustekinumab is a monoclonal antibody that decreases the expression of IL-12 and IL-23. The exact mechanism how ustekinumab works is unclear; however, it is believed that blocking of the p40 subunits of IL-12 and IL-23 reduces additional cytokine release, thus removing a crucial step for immune cell activation. This therapy has been found to be successful in patients with psoriasis [6] and due to the aforementioned similarities, it has infrequently been used for patients with unremitting PRP (table 1) [4, 7-9].

In our case, ustekinumab was determined as the best therapeutic choice due to its rapid efficacy, ease of administration and favorable side effect profile. Similar to the previously described cases, our patient also made a rapid recovery despite lack of response to other treatments. Furthermore, she demonstrated a markedly improved quality of life due to clinical efficacy in combination with the fewer required office visits as a result of the long gap between subsequent therapies. It is highly likely that ustekinumab was the source of improvement in our patient due to the significant improvement following administration and the lack of improvement following conventional therapies.

In conclusion, ustekinumab appears to be a safe and effective treatment in cases of unremitting PRP. Unfortunately, the limited number of patients with PRP and even lower numbers treated with ustekinumab do not allow us to conclude that this therapy can be used as a definitive treatment method. However, based on the previous cases and our own experience, we propose that ustekinumab can be used as an alternative agent for treatment of both acute 
Chowdhary et al.: Ustekinumab as an Alternative Treatment Option for Chronic Pityriasis Rubra Pilaris

and chronic PRP, especially in cases refractory to conventional therapy. Nevertheless, randomized, double-blind clinical studies are required to fully evaluate its safety and efficacy.

\section{Disclosure Statement}

The authors declare that there is no conflict of interests regarding the publication of this paper. Additionally, no outside funding was utilized in this study.

\section{References}

1 Klein A, Landthaler M, Karrer S: Pityriasis rubra pilaris: a review of diagnosis and treatment. Am J Clin Dermatol 2010;11:157-170.

-2 Walling HW, Swick BL: Pityriasis rubra pilaris responding rapidly to adalimumab. Arch Dermatol 2009;145:99-101.

3 Petrof G, Almaani N, Archer CB, Griffiths WAD, Smith CH: A systematic review of the literature on the treatment of pityriasis rubra pilaris type 1 with TNF-antagonists. J Eur Acad Dermatol Venereol 2013;27:e131-e135.

4 Di Stefani A, Galluzzo M, Talamonti M, Chiricozzi A, Costanzo A, Chimenti S: Long-term ustekinumab treatment for refractory type 1 pityriasis rubra pilaris. J Dermatol Case Rep 2013;7:5-9.

-5 Eastham AB, Femia AN, Qureshi A, Vleugels RA: Treatment options for pityriasis rubra pilaris including biologic agents: a retrospective analysis from an academic medical center. JAMA Dermatol 2014;150:92-94.

6 Croxtall JD: Ustekinumab: a review of its use in the management of moderate to severe plaque psoriasis. Drugs 2011;71:1733-1753.

7 Wohlrab J, Kreft B: Treatment of pityriasis rubra pilaris with ustekinumab. Br J Dermatol 2010;163:641666.

8 Mercer JM, Pushpanthan C, Anandakrishnan C, Landells ID: Familial pityriasis rubra pilaris: case report and review. J Cutan Med Surg 2013;17:226-232.

-9 Villaverde RR, Cano DS: Successful treatment of type 1 pityriasis rubra pilaris with ustekinumab therapy. Eur J Dermatol 2010;20:630-636.

M. Chowdhary and U. Davila contributed equally to this work and should be considered co-first authors. 


\section{Case Reports in Dermatology}

\begin{tabular}{l|l}
\hline Case Rep Dermatol 2015;7:46-50 \\
\hline DOI: $10.1159 / 000381011$ & $\begin{array}{l}\text { C 2015 S. Karger AG, Basel } \\
\text { www.karger.com/cde }\end{array}$ \\
\hline
\end{tabular}

Chowdhary et al.: Ustekinumab as an Alternative Treatment Option for Chronic Pityriasis Rubra Pilaris

Table 1. Summary of previous cases of PRP treated with ustekinumab

\begin{tabular}{|c|c|c|c|c|c|c|c|}
\hline $\begin{array}{l}\text { Case No. } \\
\text { [Ref.] }\end{array}$ & $\begin{array}{l}\text { Age/ } \\
\text { sex }\end{array}$ & $\begin{array}{l}\text { Onset of } \\
\text { symptoms }\end{array}$ & Prior treatment & $\begin{array}{l}\text { Ustekinumab } \\
\text { dosage }\end{array}$ & Resolution & $\begin{array}{l}\text { Time before } \\
\text { improvement }\end{array}$ & $\begin{array}{l}\text { Side } \\
\text { effects }\end{array}$ \\
\hline $1[4]$ & $31 / \mathrm{M}$ & chronic & $\begin{array}{l}\text { topical therapy, cyclosporine, } \\
\text { methotrexate }\end{array}$ & $45 \mathrm{mg}$ & complete & 4 weeks & none \\
\hline $2[7]$ & $57 / \mathrm{M}$ & chronic & $\begin{array}{l}\text { corticosteroids, retinoids, } \\
\text { methotrexate, etanercept, } \\
\text { efalizumab, adalimumab }\end{array}$ & $45 \mathrm{mg}$ & near-complete & 8 weeks & none \\
\hline $3[8]$ & $28 / \mathrm{M}$ & acute & acitretin + bath-PUVA & $45 \mathrm{mg}$ & complete & 4 weeks & none \\
\hline $4[9]$ & $45 / \mathrm{M}$ & acute & - & $45 \mathrm{mg}$ & complete & 5 weeks & none \\
\hline $\begin{array}{l}\text { Our } \\
\text { case }\end{array}$ & $52 / F$ & chronic & $\begin{array}{l}\text { topical therapy, minocycline, } \\
\text { UVB-NB, corticosteroids, methotrexate }\end{array}$ & $90 \mathrm{mg}$ & near-complete & 8 weeks & none \\
\hline
\end{tabular}

PUVA = Psoralen plus UV light therapy; UVB-NB = narrow-band UVB phototherapy.
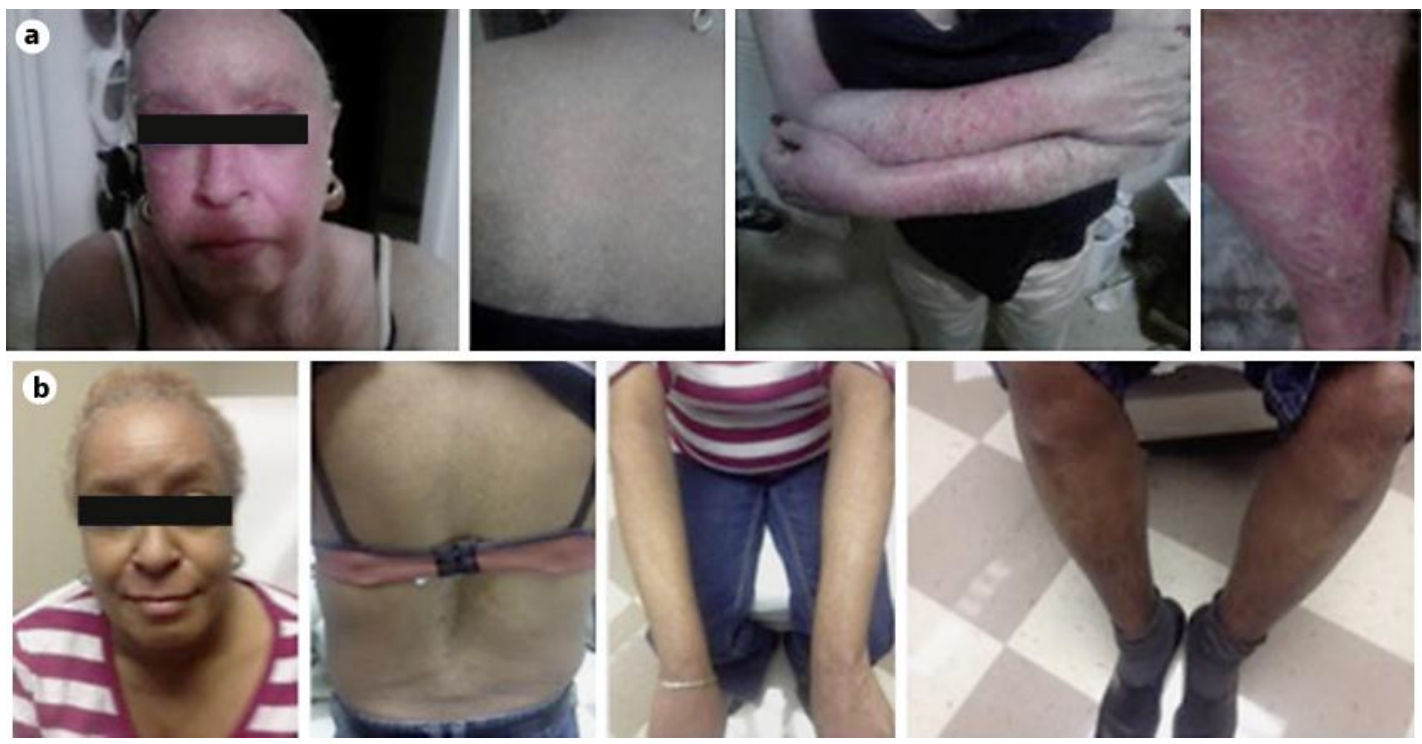

Fig. 1. Clinical appearance before and during therapy with ustekinumab: at baseline (a) and 8 weeks after subcutaneous injection of ustekinumab $90 \mathrm{mg}$ (b). 